\title{
A 32-year-old male with pain and discomfort during biting
}

\author{
Md. Abdul Hannan Sheikh, Taib Bin Badsha, Md. Joynal Abdin and Mozammal Hossain
}

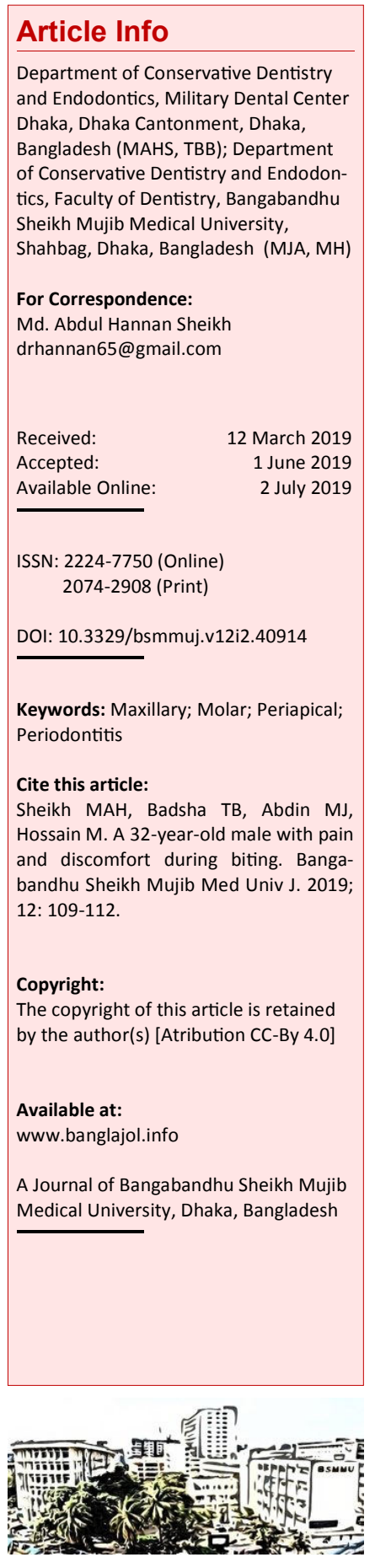

\section{Presentation of Case}

Dr. Md. Abdul Hannan Sheikh (Lt Colonel): A 32year-old male patient reported to the Department of Conservative Dentistry and Endodontics, Military Dental Center, Dhaka with the complaints of mild to moderate pain and discomfort during mastication in his upper left posterior region. His medical history was noncontributory. On extra oral examination, no abnormality was detected. On intraoral examination, clinically there was a dislodged restoration involving the upper left first molar tooth. On vitality test, the offending tooth showed no response to heat or cold. On percussion, tenderness and dull percussion note were present. There was no mobility of the associated tooth. The treatment plan was established as endodontic treatment of maxillary left first permanent molar, followed by permanent restoration with composite resin.

\section{Treatment Procedure}

Dr. Sheikh: At first, consent of the patient was taken after informing the procedure accordingly. After mouth preparation and administration of local anesthetic solution, a straight line access cavity was made with isolation by rubber dam. The pulp chamber was completely de-roofed and cleaned so that the pulpal floor can be clearly visualized. On careful exploration of pulpal floor with an endodontic explorer (DG-16) presence of six canals, namely, MB1, MB2, MB3, DB1, DB2 and $P$ were identified (Figure $1 \mathrm{AB})$. After negotiation of all canals, necrotic pulp remnants were removed and flushed out by normal saline and $2.5 \%$ sodium hypochlorite solution. Working length measuring radiograph was taken and was established at $19.5 \mathrm{~mm}$ for MB1, MB2, MB3 canal; $19 \mathrm{~mm}$ for DB1, DB2 canal and $21 \mathrm{~mm}$ for palatal canal from their respective cusps (Figure 1C). Then the canals were prepared by protaper machine using copious irrigation with $0.9 \%$ normal saline and $2.5 \%$ sodium hypochlorite solution. The canals were then soaked with $2 \%$ chlorhexidine for $1 \mathrm{~min}$ and finally $17 \%$ liquid EDTA was applied for 2-
$3 \mathrm{~min}$. Then the canals were dried with paper point and calcium hydroxide paste was placed as an intracanal medicament. Access cavity was closed with zinc oxide eugenol cement and the patient was recalled after one week.

At next appointment, the patient was found to be asymptomatic, the temporary restoration was removed and calcium hydroxide was removed by flushing with normal saline followed by sodium hypochlorite. Then final irrigation was done with $17 \%$ liquid EDTA to remove the smear layer and the canals were dried with paper point. Protaper GP cones were tried in the canals and the tooth was obturated using calcium based sealer-sealapex. A final radiograph was obtained to confirm the completeness of root fillings. The post-operative radiograph showed six separate canals (Figure 1DE). Then, the tooth was restored with composite resin. After 12 months of follow-up, no clinical or radiographic concern was apparent.

\section{Radiological Findings}

Dr. Mozammal Hossain (Associate Professor): Radiographic examination revealed slight widening of periodontal ligament space of maxillary left first molar with no definitive periapical radiolucency in the involved tooth. Considering the history, clinical and radiographical examination, it was diagnosed as a case of chronic periapical periodontitis of maxillary left first molar.

\section{Provisional Diagnosis}

Chronic periapical periodontitis of maxillary left first molar

\section{Differential Diagnosis}

\section{Acute periapical periodontitis}

Dr. Taib Bin Badsha (Postgraduate diploma trainee): There is moderate to severe spontaneous discomfort, in addition to pain on biting 

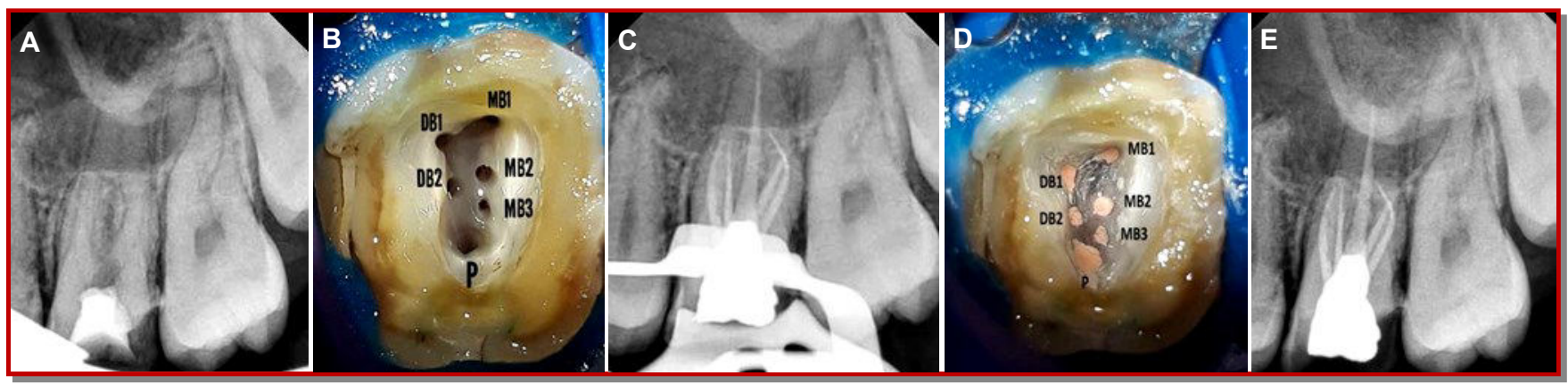

Figure 1: Initial radiograph shows exposure to pulp by filling material. The canal orifice is complex (A); Initial mirror image of the canal as mesiobuccal (MB1, MB2, MB3), distobuccal (DB1, DB2) and one palatal (P) (B); Master cone with gutta percha point was inserted to detect the canal (C); Obturation of the canal where pink color gutta percha blocked the canal (D); Radiograph of sealed canal with gutta percha point and sealer (E)

or percussion. If it is an extension of pulpitis, signs and symptoms include responsiveness to cold, heat or electricity but in necrotic pulp does not respond to vitality tests. Application of pressure by the fingertip or tapping with blunt end of mirror handle can cause marked to excruciating pain.1,2 Occasionally, there are slight radiographic changes like mild widening of periodontal ligament space or a very small radiolucent lesion may be seen.

\section{Cracked tooth syndrome}

Dr. Badsha: This syndrome is characterized by acute pain on mastication (pressure or release) of grainy, tough foods and sharp, brief pain with cold. 3 The pulp is usually responsive (vital) but may be nonresponsive (necrosis). Periapical tests also vary, but usually pain is not elicited with percussion or palpation if the pulp is vital.

\section{Chronic periapical abscess}

Dr. Badsha: Tooth with chronic periapical abscess is generally asymptomatic or only mildly painful. At times such an abscess is detected only during routine radiographic examination or the presence of sinus tract which can be either intraoral or extraoral. $\underline{4}$

\section{Lateral periodontitis}

Dr. Badsha: It is usually associated with periodontal pocket and is manifested by swelling and mild pain. The swelling is usually located opposite the midsection of the root and gingival border rather than the root apex or beyond it..

\section{Clinical Diagnosis}

Chronic periapical periodontitis of maxillary left first molar

\section{Dr. Hannan's Diagnosis}

Chronic periapical periodontitis of maxillary left first molar

\section{Discussion}

Dr. Sheikh: Although rare, variations in canal number and configuration could affect the treatment outcome. Managing these additional canals with abnormal morphology is a challenging task for every clinician. Prior to treatment, a tooth with unusual anatomical appearance on a radiograph should be carefully assessed, and additional radiographs with different angulations should be taken as its interpretation may reveal external and internal anatomic details that suggest the presence of extra canals and /or roots.

\section{Discussion on complex anatomy}

Dr. Md. Joynal Abdin (Assistant Professor): The case report being presented is that of a maxillary first molar with six root canals-three in mesiobuccal, two in distobuccal, and one in palatal. Maxillary first molars have often been an area of interest as they are known for their dissimilar morphologies and variations in the number of canals present. Most commonly, they have three roots and four canals. Special attention is always paid to the second mesiobuccal canal, which, according to many authors are commonly presents variation. ${ }_{\text {, }}$ 7 Martinez-Berna and Ruiz-Badanelli (1983)요 repor -ted the maxillary first molar with three mesiobuccal (separate canals with separate foramina). Following which few other reports have also been published. 9 The feasibility of negotiating with an unusual morphology depends upon a thorough knowledge of the normal anatomy and an awareness of the existence of anomalies. Proper access opening is key to the success of identifying and negotiating root canals. The most common design of access preparation for maxillary molars is a triangle formed by the orifices of the two buccal canals and the palatal canal. However, in the present case, a more trapezoid form of access preparation was necessary for the inclusion of all of the canal orifices.

\section{Radiographic discussion}

Dr. Hossain: The use of radiographic techniques to 
study the morphology of the root canal system might appear to have certain disadvantages. The operator can only see the tooth in a two-dimensional image, and conceivably extra root canals could be missed in the radiograph. Unfortunately, radiographs are still the most reliable method in the clinical setting. $\underline{10}$ The methods to explore additional canal orifices have always been an important area of discussion and now-a-days various tools have been used for this purpose. They are magnifying loupes and surgical operating microscope, $\underline{11}$ and examination of the pulp chamber floor with a sharp explorer, toughing of the grooves with ultrasonic tips, staining the chamber floor with $1 \%$ methylene blue dye, performing the sodium hypochlorite "Champagne bubble test," and visualizing canal bleeding points are the commonly followed methods for detection of canal orifices. $\underline{\mathbf{1 2}}$

\section{Comparison with previous studies}

Dr. Sheikh: Recent anatomical studies were able to establish the prevalence of the third canal in the mesiobuccal root. Degerness and Bowles (2010) sectioned and examined 90 uninstrumented mesiobuccal roots of maxillary first molars under stereomicroscope, and found that MB3 has an incidence of $1.1 \% . \underline{13}$ Using CBCT, Lee et al. (2011) $\underline{14}$ and Kim et al. (2012) $\underline{15}$ analyses 458 and 814 maxillary first molars, respectively, and reported a prevalence of MB3 of 1.3 and $0.1 \%$, respectively. The higher incidence of multiple canals in the mesiobuccal root as compared to the distobuccal root could possibly be due to the mesiobuccal root being broad buccolingually while the distobuccal root is round or ovoid in cross-section. $\underline{16}$

\section{Follow-up}

Dr. Sheikh: Endodontic research and technology are continually evolving to enable practitioners to identify, disinfect and obturate root canal system predictably and efficiently. Since the ultimate goal for patients and practitioners alike is the retention of natural teeth for a lifetime, endodontic therapy remains, and will continue to be, the primary treatment choice for teeth with pulpal and periradicular pathology. Knowledge of the internal dental morphology is a complex and extremely important point for planning and performing of endodontic treatment. The several anatomical variations existing in the root canal system may contribute for failure of root canal therapy. Several authors have attempted to clarify this topic and have proposed new techniques to provide a broader description of the anatomy of permanent teeth.

Dr. Ashraful Bari (Postgraduate Diploma Trainee): Would you please tell us the incidence of the same case described by different researchers?

Dr. Sheikh: The first study describing the internal dental anatomy dates back to the 19th century. $\underline{17}$ The form, configuration, and number of root canals present in maxillary molars have been discussed for more than half a century. In the beginning of the 20th century, Okumura (1927) $\underline{18}$ published his revolutionary study about the transformation of teeth into transparent blocks, revealing complex wefts that were part of root canals. Normally maxillary molars are described to have 3 roots and 3 canals ( 1 canal having each root). Literature shows wide variations in numbers and morphology of canals in each root. The mesiobuccal root of the maxillary first molar contains a double root canal system more often and the incidence of second mesiobuccal canal (MB2) has been reported to be between 18.6 and $96.1 \% . \underline{19,20}$ The incidence of second distobuccal canal (DB2) has been reported to be between 1.6 and $9.5 \% .21,22$ Apart from these anatomical variations, in extremely rare cases, the presence of a third canal in the mesiobuccal (MB3), distobuccal (DB3) and palatal roots has been reported. 11,23 The incidence of two root canals in the palatal root has been found to be 0.2 to $7.0 \% . \underline{6,19}$ Pineda and Kuttler studied the radiographs of 262 maxillary first molars and found $3.6 \%$ incidence of two distobuccal canals, with no incidence of two canals in the palatal root. $\underline{4}$ This case report intensifies the complexity of maxillary molar morphologic variation and represents successful endodontic treatment of maxillary first molar tooth with 3 roots and 6 canals. The canals are mesiobuccal (MB1, MB2, MB3), distobuccal (DB1, DB2) and 1 palatal which is rarely discussed in literature.

\section{Final Diagnosis}

Chronic periapical periodontitis of maxillary left first molar with six root canals

\section{References}

1. Mejàre IA, Axelsson $S$, Davidson $T$, Frisk $F$, Hakeberg M, Kvist T, Norlund A, Petersson A, Portenier I, Sandberg H, Tranaeus S, Bergenholtz G. Diagnosis of the condition of the dental pulp: A systematic review. Int Endod J. 2012; 45: 597-613.

2. Mitchell DF, Tarplee RE. Painful pulpitis: A clinical and microscopic study. Oral Surg Oral Med Oral Pathol. 1960; 13: 1360-70.

3. Homewood CI. Cracked tooth syndrome: Incidence, clinical finding and treatment. Aust Dent J. 1998; 43: 217-22.

4. Shimizu E, Ricucci D, Albert J, Alobaid AS, Gibbs JL, Huang GT, Lin LM. Clinical, radiographic, and 
histological observation of a human immature permanent tooth with chronic apical abscess after revitalization treatment. J Endod. 2013; 39: 1078-83.

5. Yoshida-Minami I, Kishimoto K, Suzuki A, Fujiwara T, Shintani S, Morisaki I, Sobue S, Miyamoto M, Nagai A, Kurihara H. Clinical, microbiological and host defense parameters associated with a case of localized prepubertal periodontitis. J Clin Periodontol. 1995; 22: 56-62.

6. Caliskan MK, Pehlivan Y, Sepetioglu F, Turkun M, Tuncer SS. Root canal morphology of human permanent teeth in a Turkish population. J Endod. 1995; 21: 200-04.

7. Buhrley LJ, Barrows MJ, BeGole EA, Wenckus CS. Effect of magnification on locating the MB2 canal in maxillary molars. J Endod. 2002; 28: 324-27.

8. Martinez-Berna A, Ruiz-Badanelli P. Maxillary first molars with six canals. J Endod. 1983; 9: 375-81.

9. Garg AK, Tewari RK, Kumar A, Agrawal N. Endodontic treatment of a maxillary first molar having three mesiobuccal canals with the a idofspiral computed tomography: A case report. J Oral Sci. 2010; 52: 495-99.

10. Ordinola-Zapata R, Martins JNR, Niemczyk S, Bramante CM. Apical root canal anatomy in the mesiobuccal root of maxillary first molars: Influence of root apical shape and prevalence of apical foramina: A micro-CT study. Int Endod J. 2019 (in press).

11. Wong M. Maxillary first molar with three palatal canals. J Endod. 1991; 17: 298-99.

12. Baratto Filho F, Zaitter S, Haragushiku GA, de Campos EA, Abuabara A, Correr GM. Analysis of the internal anatomy of maxillary firstmolars by using different methods. J Endod. 2009; 35: 337-42.

13. Degerness RA, Bowles WR. Dimension, anatomy and morphology of the mesiobuccal root canal system in maxillary molars. J Endod. 2010; 36: 98589.

14. Lee JH, Kim KD, Lee JK, Park W, Jeong JS, Lee Y, Gu Y, Chang SW, Son WJ, Lee WC, Baek SH, Bae
KS, Kum KY. Mesiobuccal root canal anatomy of Korean maxillary first and second molars by conebeam computed tomography. Oral Surg Oral Med Pathol Oral Radiol Endod. 2011; 111: 785-91.

15. Kim Y, Lee SJ, Woo J. Morphology of maxillary first and second molars analyzed by cone-beam computed tomography in Korean population: Variations in the number of roots and canals and the incidence of fusion. J Endod. 2012; 38: 1063-68.

16. Cleghorn BM, Christie WH, Dong CC. Root and root canal morphology of the human permanent maxillary first molar: A literature review. J Endod. 2006; 32: 813-21.

17. Naseri M, Kharazifard MJ, Hosseinpour S. Canal configuration of mesiobuccal roots in permanent maxillary first molars in Iranian population: A systematic review. J Dent (Tehran). 2016; 13: 438447.

18. Okumura T. Anatomy of the root canals. J Am Dent Assoc. 1927; 14: 632-35.

19. Hartwell G, Bellizzi R. Clinical investigation of in vivo endodontically treated mandibular and maxillary molars. J Endod. 1982; 8: 555-57.

20. Kulild JC, Peters DD. Incidence and configuration of canal systems in the mesiobuccal root of maxillary first and second molars. J Endod. 1990; 16: 311 -17 .

21. De Deus QD. Frequency, location, and direction of the lateral, secondary, and accessory canals. J Endod. 1975; 1: 361-66.

22. Sert S, Bayirli GS. Evaluation of the root canal configurations of the mandibular and maxillary permanent teeth by gender in the Turkish population. J Endod. 2004; 30: 391-98.

23. Kumar R. Report of a rare case: A maxillary first molar with seven canals confirmed with cone-beam computed tomography. Iran Endod J. 2014; 9: 153 57.

24. Pineda F, Kuttler Y. Mesiodistal and buccolingual roentgenographic investigation of 7225 root canals. Oral Surg Oral Med Oral Pathol. 1972; 33: 101-10. 